\section{Abscesos esplénicos: revisión de 7 casos}

\section{Sr. Director:}

El absceso esplénico (AE) piogénico es una patología infrecuente, de difícil diagnóstico y elevada mortalidad. La introducción de la ecografía y tomografía axial computerizada (TAC) han permitido una mayor precisión diagnóstica y terapéutica, modificando el pronóstico infausto que tenía esta entidad. Presentamos un estudio descriptivo, retrospectivo, en el hospital de Cabueñes, de 490 camas, que atiende a una población de 300.000 habitantes en Gijón. Recogimos todos los casos diagnosticados de AE por ecografía o TAC, con confirmación microbiológica o histopatológica, desde enero 1991 hasta diciembre 2005. Los AE por micobacterias o diagnosticados en otros hospitales se han excluido. Se hallaron 7 casos, 6 varones y 1 mujer, con una edad media de 66 años (35-87), cuyas principales características se describen en la tabla I. La inmunodepresión fue el factor predisponente principal, seguido de diseminación hematógena. Las manifestaciones clínicas más frecuentes fueron fiebre y dolor abdominal. La exploración fue inespecífica, con soplo cardíaco en los casos de endocarditis. Los estudios analíticos demostraban leucocitosis neutrofilica y reactantes de fase aguda. Se identificó el germen responsable en sangre y/o bazo en todos, excepto en el paciente que fue exitus. La ecografía demostró lesión focal en 5 , mientras que la TAC tuvo una sensibilidad del $100 \%$. El tratamiento antibiótico se pautó según cultivo y antibiograma, manteniéndolo entre 4-6 semanas. Se realizó drenaje percutáneo (DP) en 5 y esplenectomia en 2. Sólo hubo un exitus a las 24 horas de ingreso, que se sospechó por TC y se confirmó en autopsia. Los AE son una patología rara, con una incidencia en series de necropsias de $0,14-$ $0,70 \%$, similar a nuestra serie $0,19 \%$ (1-3). Afecta de forma predominante a varones sin que se conozcan las causas (1-3). Los primeros trabajos demostraban que $\mathrm{AE}$ afectaban a gente joven. Sin embargo, en sucesivas publicaciones se objetiva que la edad media va ascendiendo, y así en nuestro medio se encuentra en 66 años, relacionada con la mejoría en la profilaxis y tratamiento de las infecciones, y mayor esperanza de vida entre otros (1-3). En la actualidad entre las infecciones que pueden conducir la formación de AE la endocarditis aparece en primer lugar debido al alto porcentaje de embolismos en el bazo $39 \%(3,4)$. La inmunodepresión constituye el otro factor preponderante debido una mayor incidencia de bacteriemias de cualquier origen, y a una alteración de mecanismos de defensa $(2,3)$. Las manifestaciones clínicas son similares en todas las series incluida la nuestra, con predominio de fiebre y dolor abdominal (1-3,5). La exploración es poco relevante. Los estudios analíticos son similares a otros procesos piogénicos. El diagnóstico microbiológico, bien en sangre o cultivo del $\mathrm{AE}$, suele ser positivo en cerca del $90 \%$ de casos (3). Existen casos con cultivo negativo, en relación anaerobios no aislados o pacientes con antibioterapia previa. Nuestra serie refleja predominio de estreptococos, seguido de enterobacterias, debido a las características de nuestro hospital que carece de unidad de trasplantes entre otros. En las últimas series hay aparición constante de gérmenes anaerobios y hongos (3). Las técnicas de imagen son fundamentales para el diagnóstico. La ecografía abdominal es útil, sin embargo es la TAC abdominal, con una sensibilidad aproximada al $100 \%$, la técnica de elección $(2,3,6)$. En nuestro estudio la TAC fue diagnóstica en todos los casos. En la actualidad -en caso de AE único, se ha extendido el uso del DP guiado por ECO/TAC y antibioterapia como primera opción, permitiendo la conservación del tejido esplénico y su papel inmunológico, disminuyendo las complicaciones posquirúrgicas y la estancia hospitalaria (3,7-10). En caso de fracaso de DP se indicará esplenectomia. En nuestro trabajo se realizó DP en la mayoría de los casos. La mortalidad sin tratamiento es del $100 \%$ y en las series con tratamiento oscila entre $12-53 \%$, como en nuestro trabajo (3). En resumen, debemos estar alerta en pacientes con fiebre y dolor abdominal, con realización precoz de ecografía y TAC, para disminuir la morbimortalidad de esta patología.

TABLA I

\begin{tabular}{|c|c|c|c|c|}
\hline $\begin{array}{l}\text { Edad/sexo/factor } \\
\text { Predisponente }\end{array}$ & $\begin{array}{l}\text { Características } \\
\text { clínicas }\end{array}$ & $\begin{array}{l}\text { Germen/Aislamiento } \\
\text { Diagnóstico }\end{array}$ & Tratamiento & Evolución \\
\hline $\begin{array}{l}65 / \mathrm{V} \\
\text { Endocarditis }\end{array}$ & $\begin{array}{l}\text { Fiebre, distermia, } \\
\text { dolor abdominal, } \\
\text { vómitos, cuadro, } \\
\text { HEmegalia, soplo }\end{array}$ & $\begin{array}{l}\text { Enterococo (sangre, bazo) } \\
\text { ECO/TAC colección única }\end{array}$ & $\begin{array}{l}\text { ATB } \\
\text { DP }\end{array}$ & Favorable \\
\hline $\begin{array}{l}\text { 35/V } \\
\text { Inmunodepresión }\end{array}$ & $\begin{array}{l}\text { Fiebre, distermia, } \\
\text { dolor abdominal } \\
\text { HEmegalia }\end{array}$ & $\begin{array}{l}\text { Streptococo viridans (bazo) } \\
\text { ECO/TEC colección única }\end{array}$ & $\begin{array}{l}\text { ATB } \\
\text { DP }\end{array}$ & Favorable \\
\hline $\begin{array}{l}\text { 64/V } \\
\text { Endocarditis }\end{array}$ & $\begin{array}{l}\text { Fiebre, distermia } \\
\text { dolor abdominal } \\
\text { soplo }\end{array}$ & $\begin{array}{l}\text { Estreptococo grupo D (no } \\
\text { enterococo) (sangre, bazo) } \\
\text { ECO/TAC colección única }\end{array}$ & $\begin{array}{l}\text { ATB } \\
\text { Esplenectomía } \\
+ \text { recambio valvular }\end{array}$ & $\begin{array}{l}\text { Favorable } \\
\text { (UCl) }\end{array}$ \\
\hline $\begin{array}{l}\text { 62/M } \\
\text { Inmunodepresión }\end{array}$ & $\begin{array}{l}\text { Fiebre, distermia } \\
\text { cuadro sistémico }\end{array}$ & & ATB & Exitus \\
\hline $\begin{array}{l}87 / \mathrm{V} \\
\text { Inmunodepresión } \\
\text { Salmonelosis }\end{array}$ & $\begin{array}{l}\text { Fiebre, distermia } \\
\text { vómitos, dolor } \\
\text { abdominal }\end{array}$ & $\begin{array}{l}\text { Salmonella enteritidis } \\
\text { (sangre) TAC colección } \\
\text { única }\end{array}$ & $\begin{array}{l}\text { ATB } \\
\text { DP }\end{array}$ & Favorable \\
\hline $\begin{array}{l}\text { 75/V } \\
\text { Idiopático }\end{array}$ & $\begin{array}{l}\text { Fiebre, distermia, } \\
\text { dolor abdominal }\end{array}$ & $\begin{array}{l}\text { Streptococo viridans } \\
\text { (sangre, bazo) }\end{array}$ & $\begin{array}{l}\text { ATB } \\
\text { DP }\end{array}$ & Favorable \\
\hline $\begin{array}{l}77 / \mathrm{V} \\
\text { Inmunodepresión }\end{array}$ & $\begin{array}{l}\text { Fiebre, distermia, } \\
\text { Dolor abdominal } \\
\text { Esplenomegalia }\end{array}$ & $\begin{array}{l}\text { Escherichia coli } \\
\text { (sangre, bazo, pleura) } \\
\text { ECO/TAC colección única }\end{array}$ & $\begin{array}{l}\text { ATB } \\
1^{\circ} \text { DP } \\
2^{\circ} \text { esplenectomía }\end{array}$ & Favorable \\
\hline
\end{tabular}


E. M. Fonseca Aizpuru, F. J. Nuño Mateo, M. J. Menéndez Calderón, I. M. Arias Miranda, B. Rodríguez Díaz

Servicio de Medicina Interna. Hospital de Cabueñes. Gijón

1. Ooi LL, Leong SS. Splenic abscesses from 1987 to 1995. Am J Surg 1997; 174: 87-93.

2. Chun CH, Raff MJ, Contreras L, Varghese R, Waterman N, Daffner R, Melo JC. Splenic abscess. Medicine 1980; 59: 50-65.

3. Górgolas M, Fernández Giusti A, Azofra J, Ezpeleta C, Barros C, Renedo $\mathrm{G}$, et al. Abscesos esplénicos: Estudio clínico-microbiológico de quince casos. Rev Clin Esp 1991; 189: 278-82.

4. Suárez CG, Bayona JF, Rivas P, Cubero LL, Gorgolas M. Endocarditis and splenic abscesses. An Med Interna (Madrid) 2003; 20: 54-5.

5. Chang KC, Chuah SK, Changchien CS, Tsai TL, Lu SN, Chiu YC et al. Clinical characteristics and prognostic factors of splenic abscess: A review of 67 cases in a single medical center of Taiwan. World J Gastroenterol 2006; 12: 460-4.

6. Ng KK, Lee TY, Wan YL, Tan CF, Lui KW, Cheung YC, et al. Splenic abscess: Diagnosis and management. Hepatogastroenterology 2002; 49: 567-71.

7. Casado L, Hevia C, Colunga, Suárez E, Cartón JA, Arribas JM. Absceso esplénico por Salmonella enteritidis. Drenaje percutáneo con éxito en 2 pacientes. Enferm Infecc Microbiol Clin 1994; 12: 52-3.

8. Kang M, Kalra N, Gulati M, Lal A, Kochhar R, Rajwanshi A. Image guided percutaneous splenic interventions. Eur J Radiol 2007; 64: 140-6.

9. Lucey BC, Boland GW, Maher MM, Hahn PF, Gervais DA, Mueller PR. Percutaneous nonvascular splenic intervention: A 10-year review. AJR Am J Roentgenol 2002; 179: 1591-6.

10. Zerem E, Bergsland J. Ultrasound guided percutaneous treatment for splenic abscesses: The significance in treatment of critically ill patients. World J Gastroenterol 2006; 12: 7341-5.

\section{Endocarditis en electrodo de marcapasos de resincronización cardiaca. Tratamiento quirúrgico con circulación extracorpórea}

\section{Sr. Director:}

La terapia de resincronización cardíaca (TRC) con marcapaso cardiaco (MC) de Resincronización es una modalidad terapéutica establecida en determinados grupos de pacientes con insuficiencia cardiaca.

Presentamos el caso de un paciente con endocarditis tardía y de repercusión, localizada en un electrodo del sistema de MC de resincronización, tratado quirúrgicamente con éxito.

Paciente varón de 60 años, portador de un MC tricameral para resincronizacion (Guidant Contact Renewal TR) desde el 19 de abril del 2005, implantado por bloqueo trifascicular, cardiomiopatía dilatada y disfunción ventricular izquierda con fracción de eyección del $24 \%$.

El 9 de agosto de 2006 ingresó por fiebre vespertina de 4 semanas de evolución. Antecedentes personales de obesidad, diabetes mellitus no insulinodependiente y disfunción eréctil, por lo que se sometió a cirugía de implantación de prótesis de pene en junio de 2006. Tras su ingreso se realizaron hemocultivos siendo positivos para Staphilococcus epidermidis coagulasa negativo, instaurándose tratamiento antibiótico intravenoso (i.v.). Se practicó un ecocardiograma transtorácico que mostraba imagen compatible con verruga en electrodo de MC. Seguidamente se efectuó un ecocardiograma transesofágico (ETE) que demostraba una verruga grande de $7 \times 2 \mathrm{~cm}$ en el electrodo ventricular derecho (VD) (Fig. 1). A pesar del tratamiento antibiótico la evolución

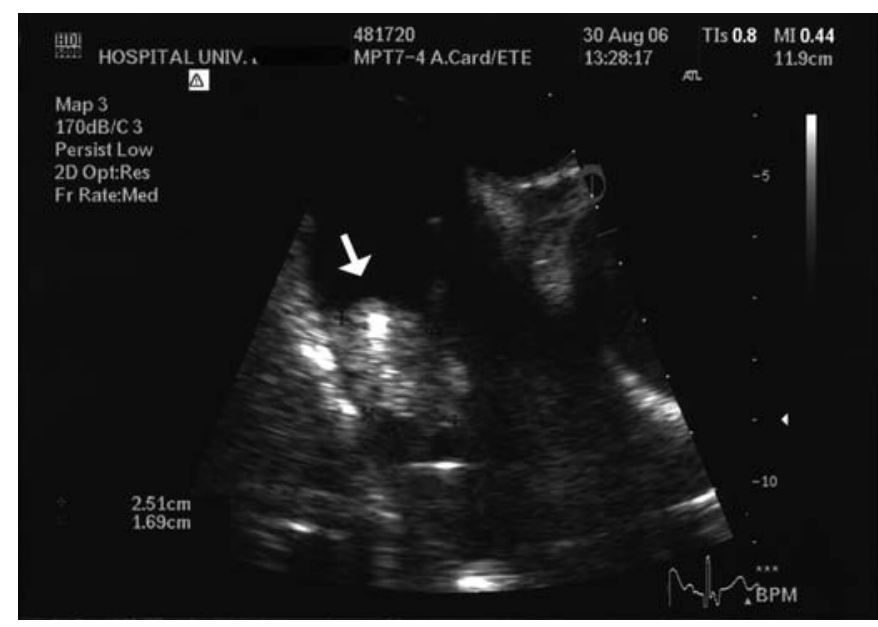

Fig. 1. Ecocardiograma transesofágico preoperatorio. Se aprecia verruga grande en la aurícula derecha en relación con electrodo.

clínica del paciente fue desfavorable, presentando shock séptico, hipotensión arterial, necesidad de inotrópicos, hemofiltración por fracaso renal e ingreso en la Unidad de Cuidados Intensivos (UCI). Ante los hallazgos y la situación clínica se decidió cirugía.

El 7 de octubre de 2006, se intervino quirúrgicamente en situación de urgencia. Se realizó una esternotomía media y bajo circulación extracorpórea (CEC), se retiró el electrodo de electroestimulación del VD con verrugas, electrodo auricular derecho (AD) y electrodo ventricular izquierdo (VI) colocado a través del seno coronario. Además fue extraído el generador situado en región pectoral izquierda. A continuación se implantó en el epicardio de VD, VI y AD tres electrodos epicardicos Medtronic (Medtronic, Inc. USA) que se conectaron a un MC de Resincronización Guidant Contak Renewal TR (Guidant Corporation. Boston Scientific. USA) que se colocó por debajo de la fascia del recto anterior izquierdo del abdomen. La cirugía fue sin incidentes con un tiempo de CEC de 45 minutos y de isquemia miocárdica de 12 minutos. El curso postoperatorio en UCI y sala de hospitalización transcurrió sin complicaciones, siendo dado de alta hospitalaria tras cuatro semanas de tratamiento antibiótico i.v. Desde entonces permanece asintomático y su MC de resincronización funciona correctamente.

La TRC es una forma de tratamiento recientemente introducida en la práctica cardiológica y aplicada a grupos seleccionados de pacientes con insuficiencia cardiaca severa y disincronía mecánica con trastornos en la conducción intraventricular (1). La mayor parte son enfermos con miocardiopatía dilatada o isquémica, habiéndose obtenido mas beneficio con esta terapia en los primeros (1).

En la última década se han expandido las indicaciones e incrementado el número de implantes de dispositivos cardiacos intracavitarios (DCI) como los MC bicamerales, dispositivos de desfibrilación implantable (DAI) y MC de resincronización simples o asociados a DAI. El aumento en el número de casos de implante se ha seguido con un incremento en el número de infecciones.

La incidencia global de infecciones en pacientes tratados de DCI es variable y oscila del 0,2 al 16\%. Según Del Río y cols (2), el $1 \%$ afecta a los electrodos del equipo.

El mejor método diagnóstico de endocarditis en los electrodos de un DCI es el ETE (3). Si el enfermo portador de un DCI tiene bacteriemia y hemocultivos positivos con ausencia de verrugas en el ETE se trata con antibióticos iv. Si además de hemocultivo positivo presenta verrugas en un electrodo, se recomienda la extracción del mismo. Según Klug y cols. (3), si las verrugas al estudio con ETE son menores de $10 \mathrm{~mm}$ se puede considerar la 